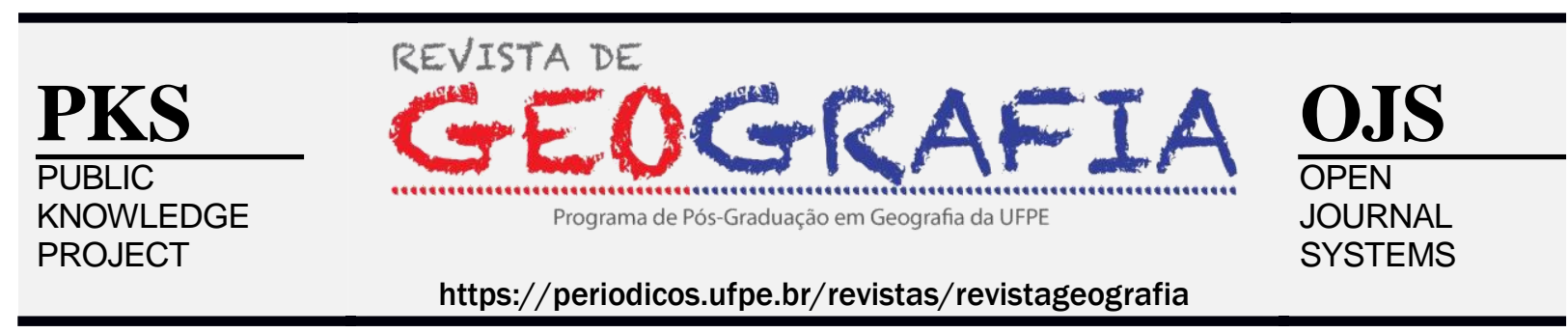

\title{
CONSIDERAÇÕES SOBRE AS PAISAGENS SEMIÁRIDAS E OS ENCLAVES SUBÚMIDOS DO NORDESTE SECO - UMA ABORDAGEM SISTÊMICA
}

\author{
Elânia Daniele Silva Araújo ${ }^{1}$, Célia Cristina Clemente Machado², Jonas Otaviano \\ Praça de $\mathrm{Souza}^{3}$
}

\begin{abstract}
${ }^{1}$ Mestre em Geografia pela Universidade Federal da Paraíba (UFPB). Professora de Geografia da rede estadual de ensin do estado da Paraíba.E-mail: elaniadani@hotmail.com

${ }^{2}$ Doutora em Geografia pela Universidade Federal de Pernambuco (UFPE). Professora do C entro de Ciências Biológicas e Sociais Aplicadas da Universidade Estadual da Paraíba (UEPB). E-mail: celiaccmachado@gmail.com

${ }^{3}$ Doutor em Geografia pela Universidade Federal de Pernambuco (UFPE). Professor Adjunto da Universidade Federal da Paraíba. E-mail: jonasgeoufpe@yahoo.com.br
\end{abstract}

Artigo recebido em 25/04/2019 e aceito em 25/11/2019

\begin{abstract}
RESUMO
O semiárido brasileiro apresenta uma diversidade paisagística, proporcionada a partir do desenvolvimento de uma variedade de formas que junto com a geologia, geomorfologia, clima, solos e vegetação propiciará a formação de diversos habitats. As paisagens semiáridas variam entre chapadas, maciços e serras baixas, planaltos, depressões e enclaves subúmidos. Baseada na abordagem sistêmica, na análise da paisagem e nos sistemas ambientais físicos, buscou-se fazer uma análise bibliográfica sobre as paisagens semiáridas e a importância das áreas de exceção dentro do semiárido brasileiro, por serem geralmente lugares com caatinga arbórea e densa, bem como pela sua importância para a população, pois impulsionam a economia local, a partir do desenvolvimento de atividades agrícolas. Constatou-se que o semiárido brasileiro apresenta uma variação paisagística, a interação entre os seus elementos abióticos, proporcionará diferentes arranjos vegetacionais, que darão margem para essa diversidade. Os enclaves subúmidos se destacam como áreas de grande importância, tanto do ponto de vista ecológico, quanto do ponto de vista social, o acaba desencadeando uma problemática relacionada a preservação e conservação desses lugares, para tanto, é necessário que haja medidas de gestão e análises para que possam ser desenvolvidas políticas de proteção as feições naturais e/ou culturais presentes no local.
\end{abstract}

Palavras-chave: Semiárido; Áreas de exceção; Caatinga.

\section{CONSIDERATIONS ON SEMI-ARID LANDSCAPES AND SUBMERGED ENCLAVES OF THE DRY NORTHEAST - A SYSTEMIC APPROACH}

\begin{abstract}
The Brazilian semi-arid presents a landscape variability, provided from the development of a variety of geology, geology, geomorphology, climate, soils and vegetation conducive to a habitat training. As semi-arid landscapes, between massifs and low saws, plateaus, depressions and submerged enclaves. Based on systematics, landscape analysis and physical data systems, a bibliographical analysis of the semi-arid landscapes and the importance of the exception areas within the Brazilian semi-arid region is sought, since it is the most common place with the arboreal and dense caatinga, as well as their importance for the population, as they boost the local economy, from the development of agricultural activities. It was verified that the Brazilian semi-arid presents a landscape variation, an interaction between its abiotic elements, offering different vegetation arrangements, that give margin to this diversity. The underwater enclaves stand out as areas of great importance, both from an ecological and social point of view, and end up unleashing a problem related to the preservation and organization of places, for
\end{abstract}

\begin{tabular}{llr}
\hline Araújo, Machado e Souza, 2019. & ISSN 0104-5490
\end{tabular}


which it is necessary to exist. So that women can have protection policies such as natural and / or cultural features present on the site.

Keywords: Semi-arid; Areas of exception; Caatinga.

\section{INTRODUÇÃO}

O semiárido brasileiro apresenta uma diversidade paisagística, conhecido pelos planaltos e depressões que ali estão localizados, o que proporciona o desenvolvimento de uma variedade de formas que em conjunto com a geologia, geomorfologia, clima, solos e vegetação propiciará a formação de diversos habitats. É essa interação dos elementos naturais que proporcionará a formação das áreas de exceção, possibilitando naquele ambiente local um diferenciado regime dos seus componentes físicos (chuvas, solo e vegetação). Essas áreas possuem uma expressiva importância, principalmente para a economia regional, porém, são ainda pouco exploradas quanto aos componentes abióticos da paisagem.

As paisagens semiáridas variam entre chapadas com altitudes acima de $800 \mathrm{~m}$, relevo acidentado e geralmente apresenta vegetação de caatinga hipoxerófila. Os maciços e serras baixas se destacam por seu relevo acidentado, solos de alta fertilidade e vegetação de florestas ou caatingas, atualmente com um alto grau de degradação. Os planaltos, o qual, pode-se trazer como exemplo a Borborema, apresentam altitudes variadas, relevo característico por dispor de vales profundos e estreitos e solos poucos profundos e de fertilidade variada. As depressões consideradas como paisagem típica do semiárido, possui uma superfície de pediplanação, com relevo predominantemente suave ondulado e cortada por vales estreitos com vertentes dissecadas, e os enclaves subúmidos, verdadeiras ilhas de umidade, que geralmente apresentam vegetação do tipo floresta perenifólia, florestas subperenifólia, florestas subcaducifólia ou matas secas, são consideradas como elementos de significativa importância para a economia regional, pois constituem setores para a produção agrícola.

Baseada na abordagem sistêmica, na análise da paisagem e nos sistemas ambientais físicos, buscou-se fazer uma análise bibliográfica sobre as paisagens semiáridas e a importância das áreas de exceção dentro do semiárido brasileiro por serem geralmente lugares com caatinga arbórea e densa, graças ao conjunto dos fatores microclimáticos, geomorfológicos e de relevo que os tornam privilegiados no sertão que o rodeia, bem como pela sua importância para a população, pois impulsionam a economia local, a partir das atividades agrícolas.

\section{SISTEMAS AMBIENTAIS FÍSICOS}

As pesquisas relacionadas a estudos sistêmicos utilizando a análise integrada da natureza e a inter-relação de suas partes datam desde 1750, com a publicação da carta geográfica 
da natureza de Abade Jean-Louis Giraud Soulavie. Essa abordagem também pode ser identificada nos trabalhos naturalistas de Humboldt e Dokuchaev, mas foi em 1950 com a formulação da Teoria Geral dos Sistemas de Bertalanffy, que houve a tentativa de construir uma linguagem comum para a análise sistêmica em diferentes disciplinas (CAVALCANTI, 2013).

Um sistema, por sua vez, baseia-se numa totalidade que é criada pela integração de seus componentes, ou seja, encontram-se organizados para exercer uma função particular, e dessa forma o seu grau de organização permite que assuma função de um todo que é maior do que a soma de suas partes. A natureza seria concebida de forma integrada, se fazendo impossível a sua compreensão a partir dos elementos separados, visto que a fragmentação do objeto pode implicar num obscurecimento das relações de interdependência entre as partes de um todo e que constituem a realidade principal (CHRISTOFOLETTI, 1979; SCHEIDEGGER, 1992; BRANCO, 1989; HAIGH, 1985).

Um sistema é composto por matéria, energia e estrutura. A matéria será o material móvel, ou seja, aquilo que vai se movimentar. A energia, será a força (ou forças) que fazem o sistema funcionar, o que possibilitará a geração de criação de trabalho e a estrutura é formada pelos elementos e suas relações, essa estará expressa pelo arranjo de seus componentes (CHRISTOFOLETTI, 1979).

De acordo com Gregory (1992), a incorporação da abordagem sistêmica na Geografia Física se inicia por volta de 1935, com a criação do conceito de ecossistema pelo ecólogo A. G. Tansley. A partir de então, torna-se uma das principais condutoras das pesquisas geográficas envolvendo seus elementos físicos. A incorporação do pensamento sistêmico nos estudos geográficos visa interpretar a complexidade que explica a organização de um sistema espacial, a partir das interações que se processam entre os atributos formadores que acabam por lhes conferir caráter dinâmico e não-linear (MARQUES NETO, 2008).

Dentro da Geografia Física, utilizando a abordagem sistêmica no que diz respeito aos estudos geomorfológicos, especificamente, se fez necessária a incorporação do termo “Equilíbrio" entre as décadas de 1950 e 1960 (RENWICK, 1992). O equilíbrio dinâmico pode ser entendido como o ajustamento completo das variáveis internas mediante às condições externas, de modo que haja um equilíbrio entre essas forças atuantes na evolução do modelado (HOWARD, 1973). A teoria do equilíbrio dinâmico se apresenta como uma evolução dos estudos geomorfológicos baseados nos preceitos sistêmicos da teoria geral dos sistemas, a sua 
aplicação pode se caracterizar como uma alternativa aproximada para a interpretação da paisagem, a partir das relações espaciais com o sistema de drenagem (FIERZ, 2016).

Relacionado aos estudos dos sistemas, surge no final do século XX, a Teoria dos Sistemas Dinâmicos como forma de entender o conjunto de objetos agrupados por alguma interação em que existem relações de causa e efeito entre os elementos do conjunto. O sistema é tido como dinâmico quando algumas grandezas variam no tempo, tais grandezas é que caracterizam seus elementos constituintes, esses sistemas podem ser simples ou complexos (LIMBERGER, 2006). Podem ser definidos como simples quando há um conjunto de componentes relacionados e agindo sobre outros a partir de determinadas leis. Por outro lado, sistemas complexos, por manterem um padrão de organização e uma característica não-linear, não buscam a análise da separação das partes, mas visam analisar a integração dos seus elementos. Além disso, sistemas complexos são caracterizados por apresentarem diversidade de elementos, encadeamentos, interações, fluxos e retroalimentação.

Baseado na perspectiva sistêmica, a qual tem por objetivo o estudo integrado dos elementos, surge a análise por meio dos Geossistemas, essa, é tida como essencial dentro da Geografia Física, chegando a ser considerada como o objeto de estudo desta área do conhecimento (SOTCHAVA, 1977; CHRISTOFOLETTI, 1990). O Geossistema é apresentado como sinônimo de Sistemas Ambientais Físicos (que são tidos como a organização espacial) e são definidos como um sistema natural, não necessariamente homogêneo e característico por possuir morfologia, funcionamento e comportamento específico (CHRISTOFOLETTI, 1990; MANTELATTO e CHRISTOFOLETTI, 2001).

A análise da paisagem, por meio do Sistemas Ambientais Físicos, levará em consideração a interação entre os elementos abióticos, tendo o clima como elemento controlador dos processos e da dinâmica, constituindo-se como fornecedor de energia, respaldando, dessa forma em seus componentes bióticos, como a vegetação, permitindo uma análise integrada de seus componentes.

\section{PAISAGENS E UNIDADES DE PAISAGEM}

As primeiras concepções de paisagem estão voltadas para o natural, visual e estético, estando explicitas nas pinturas naturalistas e na própria obra de Humboldt, na qual o autor fazia a descrição e a pintura das áreas naturais, por onde passava. A escrita humboldtiana está pautada na observação, se fazendo necessário ver, ouvir e sentir a paisagem, além de representá-las por meio da pintura que para ele era tão importante quanto a própria escrita (VITTE, 2010). A 
representação da paisagem está ligada a diversas possibilidades do maravilhoso conectando natureza e cultura, adquirindo forma de perfeição numa estética romântica, estando sua existência atrelada a uma afinidade eletiva entre a natureza e a cultura, permitindo a definição de paisagem e a atribuição de uma identidade (GOETHE, 1992; VITTE, 2007).

No sentido etimológico, a palavra paisagem é dotada de vários significados, variando entre os países e as diversas línguas, na França remete ao sentido de região, território, nação, em hebraico relaciona-se com algo maravilhoso, em inglês diz respeito a organização dos campos, estando também associada a cenário e em holandês deriva do alemão significando unidade de ocupação humana (CHRISTOFOLETTI, 1999; SCHAMA, 1996; PRIGILL e VOLKMAN, 1998). Em todos os significados, o termo paisagem associa-se a uma conotação espacial, o que a faz ser caracterizada sob duas perspectivas: estética, a qual corresponde a uma representação voltada para a aparência estética, e/ou geopolítica, designando uma unidade territorial para desenvolvimento de comunidades humanas (VITTE, 2007).

O Romantismo, como movimento cultural, veio auxiliar na formação do conceito de paisagem na Geografia e então é instituída uma nova dimensão à categoria tempo, o que possibilita a valorização das singularidades e atribui a cada comunidade e nações uma identidade própria (GOMES, 1996). Mas é desde quando Humboldt compõe "Os Quadros da Natureza", influenciado por Kant e Goethe, que a paisagem se concretiza nas pesquisas geográficas (VITTE 2010). Se tornando efetivamente objeto de estudo da Geografia quando é definido que o campo de trabalho dessa é a superfície terrestre, limitando a Geografia a observar e descrever o que é visível, tornando o espaço lito-bio-atmosférico como objeto de investigação (MENDOZA et al, 1988).

$\mathrm{Na}$ busca de reunir todas as ciências que tratam sobre o estudo das paisagens surge a Ecologia de Paisagem, com a finalidade de melhor compreensão dos aspectos ecológicos e dos limites dos ecossistemas. A Ecologia de Paisagem também tem por característica estudar as interações dos organismos em seu ambiente, essas interações envolvem processos, que por sua vez são dinâmicos, pois são variáveis no tempo. A partir desta concepção surge a noção de georelevo, dentro da dinâmica dos integrantes sistêmicos da paisagem. O conceito surge dentro da Ecologia de Paisagem e é responsável pela definição de uma estrutura territorial que apresenta um determinado potencial biológico e de ocupação, portanto, pode ser entendido como indicador dos processos morfoclimáticos atuais, o que resulta na dinâmica das formas e propriedades adquiridas em sua gênese, por sua vez, a dinâmica e as propriedades são 
fundamentais para a compreensão da evolução e dos processos geoecológicos e de reprodução/ocupação da sociedade (CASSETTI, 1991; VITTE, 2007).

É importante compreender a paisagem como sendo o resultado de uma relação entre os processos passados e os atuais, e como os processos de formação desta paisagem agem sobre as superfícies criadas por esses eventos passados. A influência histórica pode explicar, por exemplo, os processos de erosão e deposição ao longo do tempo. Assim, os processos passados têm sido responsáveis pela compartimentação regional da superfície, enquanto os atuais respondem pela dinâmica atual das paisagens. De tal modo, cada paisagem é única, com sua própria história de eventos formativos (PHILLIPS 2007; BESSE, 2006; PHILLIPS, 2001; AB'SÁBER, 1969).

Os eventos e processos que modificam a paisagem ao longo do tempo e da sua história, são de fácil identificação nos tipos de paisagens fluviais e hidrológicas, a partir da ação da água que também se constituirá como um agente modificador de significativa importância. As paisagens fluviais são caracterizadas por terem o rio como elemento principal na sua origem e dinâmica, nela estão incluídos o canal natural, as ribeiras e a planície de inundação em suas duas margens. A água configura-se como elemento essencial, organizador e dinamizador dos sistemas fluviais, nesse caso, qualquer modificação que afete as características hidrológicas será manifestada na paisagem. Dessa forma, a análise global e histórica é de grande importância, visto que, permite a melhor compreensão das dinâmicas e processos que geraram estas paisagens (PRICHOA et al., 2014; MOLINA, 1992; DUPUIS-TATE, 1998).

Como ferramenta de análise paisagística, a classificação por unidades de paisagem auxilia o entendimento das mesmas, delimitando-as a partir de setores homogêneos, na qual, busca-se pelas descontinuidades da paisagem e assim pode ser definida por uma síntese de características justificadas pela homogeneidade. Essa homogeneidade pode estar reduzida aos indicadores ambientais mais importantes, como a vegetação e a geomorfologia. Portanto, a delimitação por unidades de paisagem a partir das descontinuidades, e favorecendo os elementos integradores, caracteriza-se como uma proposta holística para os estudos ambientais e que, por sua vez, facilitam a análise como um todo e não a partir da fragmentação dos seus elementos (BERTRAND, 1971; DALBEM et al., 2005).

A identificação das unidades de paisagens tem especialmente uma relação com os estudos geomorfológicos, visto que, o estudo do relevo apresenta um potencial ecológico, devido a sua interação com a exploração biológica, através das teorias genéticas, das escalas taxonômicas, da cartografia geomorfológica, da abordagem integrada sistêmica e da relação 
espaço temporal, dessa maneira, é de grande importância para a compreensão da paisagem geográfica (FRANÇA et al., 2010).

A classificação por Unidades de Paisagens pode se individualizar a partir do relevo, clima, vegetação, solos, tipo de litologia ou exclusivamente por um desses elementos (ROSS, 1992), apresentando propriedades que provêm das relações de conexão e interação causal entre seus elementos. Ao mesmo tempo, exibem complexas delimitações que ocupam determinado espaço e tempo, sua existência é condicionada pelo funcionamento de seus elementos (CERVANTES-BORJA e ALFARO-SÁNCHEZ, 1998; MONTEIRO, 2000). Estas unidades podem ser identificadas pelos aspectos que as caracterizam interiormente, além das características que as diferenciam estando em seu entorno, esses aspectos expressam o sistema dinâmico de vários fatores interligados (DALBEM et al., 2005).

Assim, as paisagens, especialmente as semiáridas, por meio de sua diversidade, são uma expressão concreta, da relação entre os processos passados e os atuais, bem como da interação entre seus processos de formação a partir do sistema geomorfogenético que juntamente com o clima semiárido determinam a categorização das unidades de paisagem.

\section{PAISAGENS SEMIÁRIDAS}

O semiárido brasileiro se caracteriza por apresentar precipitação média anual inferior a $800 \mathrm{~mm}$, temperaturas médias altas, a partir de $27^{\circ}$, evapotranspiração potencial média de 1800 $\mathrm{mm}$, podendo chegar a $3000 \mathrm{~mm}$. Para a classificação de um ambiente árido ou semiárido é aplicado o índice de aridez elaborado por Thornthwaite (1948), o cálculo é obtido a partir da diferença entre a quantidade de chuva e a evapotranspiração, se os valores obtidos variarem entre 0,21 < 0,50, tem-se uma área semiárida. Nesses ambientes o volume de precipitação é inferior ao de evapotranspiração causando um déficit hídrico. Tais condições desfavorecem o escoamento, principalmente quando o desvio padrão anual das chuvas é muito alto, dificultando o armazenamento e infiltração de água. O escoamento superficial, geralmente existe quando ocorrem chuvas convectivas concentradas em um tempo mais curto (MATALLO JUNIOR, 2003; MMA, 2010).

O Nordeste seco denominado por Ab’Sáber (1999) e sertão nordestino por outros autores, hoje é intitulado corretamente de Semiárido brasileiro pelo fato de sua delimitação atual abranger o norte do estado de Minas Gerais, que por sua vez, não pertence a região Nordeste, possui uma área de aproximadamente $982.563,3 \mathrm{~km}^{2}$, sua delimitação atual foi instituída em 2017 pelo Ministério da Integração Nacional (MIN), levando em consideração três critérios técnicos: Precipitação pluviométrica média anual inferior a 800 milímetros; Índice 
de aridez de Thornthwaite igual ou inferior a 0,50 no período entre 1981 a 2010; e o Percentual Diário de Déficit Hídrico igual ou superior a $60 \%$, estando dentro desses três critérios, o município passa a integrar a área semiárida brasileira (MIN, 2017).

O semiárido brasileiro diferencia-se dos demais do planeta, isso por ser caracterizado como o mais chuvoso e o mais populoso, é uma das poucas regiões semiáridas do mundo com clima tropical. Sua proximidade ao equador o singulariza ainda mais, ou seja, não há ocorrência de neve no inverno e de aporte de água de degelo como é o caso da área semiárida do Chile, além do seu relevo composto por maciços e chapadas acima de $1000 \mathrm{~m}$ de altitude que permite alimentar os reservatórios de drenagem exorreica ao seu redor durante 5 a 7 meses (MALVEZZI, 2007; FUNDAJ, 2002; PASSOS e DUBREUIL, 2004).

A cobertura vegetal é dominada pelo bioma caatinga, uma palavra indígena, de origem tupi, que significa "mata-branca", devido a seu aspecto esbranquiçado quando perde suas folhas no período seco como forma de adaptação a irregularidade das chuvas na região. Essa queda das folhas é essencial para evitar a perda excessiva de água, pois com a diminuição da turgescência, as raízes vão em busca de água nas camadas mais profundas do solo, por tal motivo, haverá um acúmulo da biomassa na raiz, em detrimento da parte aérea (PIMENTEL, 2004; LIMA, 2017). Esse fator está combinado a outras formas de adaptação, como a cor mais clara da casca para diminuir o aquecimento do tecido vivo da planta, a cor verde do caule para contribuir com a fotossíntese sem aumentar a superfície da planta colaborando com a eficiência vital e o armazenamento de água seja no caule, ou nas raízes a exemplo das cactáceas e do umbuzeiro (MAIA, 2004; VELOSO et al., 1992).

Contemporaneamente, a caatinga está dentro da classificação de matas ou bosques secos, e é uma das florestas tropicais mais ameaçadas do mundo, com menos de $10 \%$ da sua extensão original, embora essa tenha sido classificada como vegetação de savana, caracteriza-se por ter um dossel fechado, diferenciando-se de uma savana mais aberta e rica em capim (VELOSO et al., 1992). Esse tipo de vegetação geralmente se desenvolve em regiões entre 20 e $10^{\circ}$ de latitude, recobrem cerca de $2,4 \%$ da superfície terrestre e caracterizam-se por suportarem um longo período de estação seca, é por esse motivo que podem perder entre 50 e $100 \%$ de sua folhagem (CREEL, 2009; BANDA et al., 2016).

A formação vegetação de caatinga é encontrada apenas no semiárido brasileiro, apresenta diversas características morfo-anatômicas e fisiológicas distintivas em resposta, principalmente, ao regime intermitente e reduzido da precipitação, bem como, ao tipo de solo e topografia. Suas espécies podem variar, desde perenifólia até decíduas ou caducifólias, o que 
dependerá do seu grau de sazonalidade e do potencial de reidratação e controle de perda de água (REICH e BORCHERT, 1984). A predominância nesse ambiente são as espécies decíduas, que também irá apresentar uma variação no grau de deciduidade de acordo com a reação aos déficits hídricos, desse modo, algumas espécies irão perder as folhas imediatamente após a estação chuvosa e assim permanecerão entre quatro e seis meses e outras irão se manter até o final da estação seca, dessa maneira, permanecem sem folhas de dois a três meses, ou seja, por um intervalo mais curto (TABARELLI et al., 2003).

Embora possua uma diversidade biológica significativa se comparada a outras áreas semiáridas do planeta, ocorre em uma região que sofre expressivamente com a interferência antrópica. Estima-se que cerca de $45 \%$ já foi desmatada e as áreas que ainda restam estão em contínuo processo de fragmentação (MALVEZZI, 2007; SANTOS et al., 2007; LOIOLA et al., 2012; MMA, 2010; CASTELLETTI et al., 2004; INPE, 2015).

Com relação a geologia, cerca de $80 \%$ é de formação de rochas cristalinas, especialmente xistos e gnaisses. Essa predominância culminará em solos rasos que, consequentemente, fará com que haja baixas trocas de água entre o rio e o solo, dificultando a infiltração da água, resultando na existência de uma densa rede de rios temporários e classificando o semiárido como uma região de baixo potencial hidrogeológico. Além disso, $85 \%$ da região semiárida é composta por depressões interplanálticas, situadas entre maciços antigos e chapadas eventuais, formando intermináveis colinas sertanejas (CIRILO, 2008).

A região semiárida brasileira apresenta uma diversidade paisagística ainda pouco conhecida quanto a sua biodiversidade, os planaltos e depressões apresentam uma expressiva variedade de formas no conjunto de sua geologia, geomorfologia, clima, solos e vegetação, essa interação possibilitará a formação de diversos habitats e diferentes tipos de vegetação. Geologicamente, a região foi dividida em três áreas de acordo com a natureza do material originário: (1) as áreas do cristalino, com predomínio de gnaisses, granitos, migmatitos e xistos; (2) as áreas recobertas por rochas sedimentares, mais ou menos arenosos e (3) áreas sedimentares recentes de depósitos fluviais (JACOMINE 1996; SUDENE, 1974).

As chapadas são grandes unidades de relevo do semiárido que se destacam por apresentarem uma altitude superior a $800 \mathrm{~m}$, platôs altos e extensos, possui solos profundos e pobres, vegetação de caatinga e cerrado. A exemplo, pode-se citar a chapada do Araripe (PE/CE), a Ibiapaba (CE) e a Chapada Diamantina (BA/MG) apresentando esta última, uma altitude que varia entre 600 e $1.300 \mathrm{~m}$ e seu relevo é geralmente acidentado, embora disponha de grandes superfícies planas. Seus solos são profundos, porém muito pobres nos topos dos 
platôs, e bastante rasos e pedregosos nas áreas de relevo acidentado. A vegetação é variada, sendo a maior parte do tipo caatinga hipoxerófila.

Destacam-se também os Maciços e Serras Baixas, com altitude entre 300 e 800 m, ocupa parte dos estados do Ceará, Pernambuco, Paraíba e Rio Grande do Norte, tem característica de relevo pouco acidentado, com solos de alta fertilidade, a vegetação primitiva, apresenta-se atualmente muito degradada, podendo ser de florestas ou de caatingas.

Outra unidade de relevo é o planalto da Borborema, que se destaca como um expressivo exemplo dentro do semiárido, é uma unidade formada por maciços e outeiros altos, com altitude variando entre 650 e 1.000 m. Estende-se desde o sul de Alagoas até o Rio Grande do Norte, seu relevo dispõe de vales profundos e estreitos e seus solos são pouco profundos e de fertilidade variada. A vegetação, em sua maioria, é de caatinga hipoxerófila, porém com grandes áreas de caatinga bastante seca nos Cariris e trechos de florestas perenifólia, subcaducifólia e caducifólia nos brejos de altitude da parte leste do Planalto.

Trata-se de uma área que se originou através de processos epirogenéticos e sucessivos aplainamentos escalonados ocorridos ao longo do Cenozoico e geologicamente predominam rochas do Pré-Cambriano, caracterizando-se por ser um planalto cristalino (SILVA, 2012; CORRÊA et al., 2010). De modo geral, possui uma estrutura elevada e de topografia irregular, sua maior extensão encontra-se em ambiente semiárido. As áreas elevadas da Borborema além de uma maior altitude, diferenciam-se pelo clima mais úmido, temperaturas mais amenas e solos mais profundos e com maior teor de matéria orgânica e presença de uma vegetação úmida com característica de floresta.

Tal quadro é resultante da disposição leste-oeste do planalto, que será primordial para exercer uma influência na paisagem natural da região, o fato de estar voltado para o oceano Atlântico a barlavento, faz com que receba as massas de ar úmidas que irão produzir chuvas orográficas e garantem uma maior umidade local, em contrapartida a região a sotavento, ou seja, a parte oeste voltada para o sertão, recebe essas massas de ar bem secas, não havendo como provocar as chuvas locais. Tal situação torna o planalto da Borborema como elemento diferenciador da paisagem local e explica a particularidade das áreas mais elevadas (ARAÚJO FILHO, 2011; CORRÊA et al., 2010).

A última grande unidade de relevo do semiárido é a Depressão Sertaneja, considerada a paisagem típica do semiárido, possui uma superfície de pediplanação bastante monótona, com relevo predominantemente suave ondulado e cortada por vales estreitos com vertentes dissecadas. Embora elevações residuais e cristas destacam-se no horizonte, sua existência pode 
ser explicada através dos ciclos intensos de erosão que no passado atingiram grande parte do sertão nordestino. A vegetação predominante é a caatinga hipoxerófila nas áreas menos secas, e a caatinga hiperxerófila nas áreas de seca mais acentuada. Estende-se por grande parte dos estados do Ceará, Rio Grande do Norte, Paraíba e Pernambuco, já na Bahia, chega até Feira de Santana e, a leste, ocupa a calha do rio São Francisco, chegando até a região de Pirapora em Minas Gerais (SÁ et al., 2004).

Como já foi mencionado, o clima destaca-se pela escassez e irregularidade das chuvas com variação entre 250 e $800 \mathrm{~mm} / \mathrm{ano}$, restrita a poucos meses do ano, porém, é necessário frisar que nas áreas de serras, que possuem uma variação de altitude, as chuvas podem chegar a atingir até $1.500 \mathrm{~mm} / \mathrm{ano}$ (ROCHA, 2009). Os solos da região têm relação direta com o clima, material de origem, relevo e vegetação, sendo de maiores ocorrências os Latossolos e Argissolos, além da ocorrência de Neossolos Quartzarênicos, Planossolos, Cambissolos, Vertissolos, Luvissolos, geralmente caracterizam-se por serem pouco profundos e suscetíveis a erosão (CODEVASF, 1999).

Áreas de geologia cristalina pode resultar na formação de aquíferos fissurais, ou seja, que são oriundos de águas presentes nas fraturas das rochas, geralmente de produtividade fraca, enquanto em terrenos sedimentares os aquíferos são denominados porosos, originados das rochas sedimentares, são mais susceptíveis a poluição, por ser superficial e pouco profundo.

Essa resposta da hidrologia superficial aliada a hidrogeologia e aos tipos de rochas, manifesta-se diretamente na vegetação, que irá variar: nas áreas de topografia mais elevadas, apresentará uma característica de vegetação mais úmida perenifólia ou semideciduais, por outro lado nas áreas de encostas e inselbergs em que predominam rochas cristalinas e em geral, apresentam um potencial hidrogeológico muito fraco a vegetação é mais seca ou caatinga arbórea, o que já é denominado por diversos autores de "caatingas" por haver essa diversidade de formações (FEITOSA et al., 2004; LEAL, et al., 2003).

A denominação "Caatingas" mostra as diferentes fitofisionomias da vegetação de modo, que as diversas nomenclaturas como caatinga arbórea, arbustiva, etc. são reunidas dentro de um grupo passando a ser chamado de "Caatingas" no plural. Também é atribuída essa nomenclatura devido ao fato da vegetação não se restringir a região geográfica nordestina, sendo também encontrada, por exemplo, no vale seco do rio Jequitinhonha em Minas Gerais (PRADO, 2003; ANDRADE-LIMA 1981).

A maior parte das caatingas estão localizadas nas depressões Interplanálticas, porém existem as áreas de exceção como a chapada do raso da Catarina, a faixa da Borborema na 
Paraíba, ou o platô Apodi no Rio Grande do Norte, nesse caso, a vegetação também é encontrada nos planaltos e é justamente essa diferenciação dos fatores abióticos das áreas, em termos de, relevo, geologia, solos e clima local, que resultará na resposta hidrológica superficial e favorecerá a diversidade da vegetação (PRADO, 2003; ANDRADE-LIMA 1981; AB'SÁBER 1974).

\section{SERRAS ÚMIDAS E ENCLAVES SUBÚMIDOS EM ÁREAS SEMIÁRIDAS}

O semiárido brasileiro também se caracteriza por apresentar áreas que irão se diferenciar, principalmente por sua disposição orográfica que possibilitará um desenvolvimento diferenciado do regime de chuvas, solos e vegetação. Tais áreas são denominadas como "áreas de exceção" dentro dos espaços secos, sendo o principal exemplo relacionado aos planaltos sedimentares, como a Chapada do Araripe, Serra da Ibiapaba e as áreas elevadas da Borborema.

Um dos pioneiros a tratar dessas áreas de exceção no Brasil foi Ab’Sáber (1999), que iniciou essa discussão denominando-as de brejos de altitude ou serras úmidas que de acordo com o autor, essas constituem verdadeiras ilhas de umidade propiciando solos férteis em variados pontos dos sertões secos. Essas áreas conseguem mudar a monotonia das condições físicas e ecológicas dos sertões secos, enriquecendo a produtividade agrária local e sendo palco de agrupamentos de nascentes ou fontes, dispondo de uma significativa importância.

Outra classificação para essas áreas de exceção dentro do semiárido seco são os enclaves subúmidos, alguns autores colocam-nas como sinônimo dos brejos de altitudes como é o caso de Bértad et al. (2007). Se assemelham as outras classificações por se constituírem também como áreas úmidas de exceção climática em meio as terras secas, porém são montanhas isoladas de altitudes médias ou baixas $(600-1200 \mathrm{~m})$ e possuem superfícies de piso aplainados. Constituem-se como barreiras aos alísios úmidos o que irá favorecer uma pluviosidade elevada (1200-2000mm/ano) (BÉTARD et al., 2007). As áreas de enclave subúmido do Nordeste, apresenta, algumas diferenciações, quanto a associação, embora haja sempre uma predominância dos Argissolos (eutróficos ou distróficos), dos Neossolos Litólicos eutróficos e dos Latossolos. Essa variação dos solos depende dos diferentes modos de relação entre os seus fatores de formação, especialmente do clima, relevo e material de origem (SOUZA e OLIVEIRA, 2006; BÉTARD et al., 2007).

Quanto ao uso da superfície pela população, as áreas mais úmidas e de solos mais profundos como é o caso dos enclaves da Serra de Baturité o Planalto da Ibiapaba e Chapada do Araripe, estarão fortemente associadas a utilização agrícola e de extração madeireira, causando um intenso desmatamento. Já as áreas dos enclaves do Brejo da Borborema (PB, PE, 
AL) são destinadas a policultura associada à pecuária mista e bovinocultura mista (corte e leite) (SOUZA e OLIVEIRA, 2006).

Essas ilhas de umidade geralmente apresentam vegetação do tipo floresta perenifólia denominada também de mata úmida ou de matas serranas plúvio-nebulares, que são características de áreas mais úmidas. Apresentam também florestas subperenifólia, florestas subcaducifólia ou matas secas, cerrados e cerradões, além das faixas de transição entre caatinga hipoxerófila/cerrado e cerrado/ floresta (SOUZA e OLIVEIRA, 2006; BÉRTAD ET al., 2007). Geralmente as espécies encontradas nessas áreas são da família Myrtaceae, Rubiaceae, que são típicas de matas úmidas, e Asteraceae, Apocynaceae, Euphorbiaceae, espécies consideradas bem representativas na caatinga (RODAL et al., 2005; PEREIRA et al., 2010).

A cobertura vegetal desses ambientes tem sofrido forte interferência antrópica, na maioria dos casos vegetação original encontra-se bem reduzida e após sua retirada, se o solo não tiver aproveitamento agrícola, irão se instalar formações secundárias, resultado do rebroto de tocos e raízes, germinação de sementes caídas, bem como a penetração de espécies invasores. Essas formações passam por diferentes estágios de desenvolvimento e quando não há forte degradação dos recursos naturais, existirá uma tendência para uma dinâmica progressiva, ou seja, sua regeneração tende para condições ecológicas próximas das formações originais. Por outro lado, se houver a degradação do solo a dinâmica é regressiva e as condições dos recursos naturais tendem a uma deterioração, geralmente ocorre em vertentes mais íngremes, e a vegetação que irá se instalar terá uma característica mais resistente as condições antrópicas, como espécies arbustivas ou arbóreo-arbustivas componentes da comunidade de cerrados ou das caatingas (SOUZA e OLIVEIRA, 2006).

Essas áreas representam 5\% do sertão e são consideradas como elementos de significativa importância para a economia regional, pois constituem setores para a produção agrícola. Apesar de sua fundamental importância, são áreas ainda pouco exploradas, principalmente no que diz respeito aos componentes abióticos da paisagem (BÉTARD et al., 2007 e SOUZA e OLIVEIRA, 2006).

A serra da Ibiapaba de natureza sedimentar, localizada no estado do Ceará, é um exemplo de enclave úmido dentro da região semiárida, dessa maneira é classificada como uma área de condições climáticas mais agradáveis do estado, está situada numa região de barlavento e dessa maneira possui maior diversidade de fauna e flora. Constituída por rochas predominantemente arenitos grosseiros com intercalações de arenitos finos, micáceos e laminados, possui uma altitude média entre 700 e $800 \mathrm{~m}$, a pluviometria média anual é superior a $1.100 \mathrm{~mm}$. Dispõe de 
uma floresta subperenifólia, porém, com poucos resquícios e um tanto descaracterizada. Nos pés-de-serras subúmidos apresenta uma mata subcaducifólica que se associa com a caatinga arbórea e densa (PEIXOTO E SALES, 2012; SOUZA FILHO E SALES, 2009).

O maciço da Serra da Baixa Verde, individualizada por ser um maciço residual, também se enquadra como uma área de exceção dentro do semiárido, está localizado no centro norte do estado de Pernambuco e integra o alto divisor hidrográfico entre os estados de Pernambuco e Paraíba. Encontra-se em terrenos cristalinos da Província Estrutural da Borborema e devido à disposição do relevo e sua altitude de aproximadamente $1.100 \mathrm{~m}$ e uma maior umidade, irá apresentar nas áreas acima de $900 \mathrm{~m}$ uma vegetação de floresta estacional subcaducifólia também conhecida como mata (CORRÊA, 2001).

Outra área de exceção inserida no semiárido e caracterizada como um enclave é a Chapada do Araripe, situa-se no extremo sul do estado do Ceará e é caracterizado como uma das áreas mais singulares dentre as áreas úmidas de exceção do contexto semiárido nordestino, seus níveis altimétricos são em torno de 850 à $900 \mathrm{~mm}$. Sua geologia é composta por materiais pertencentes à bacia sedimentar do Araripe, que se expande pelos Estados do Ceará, Pernambuco e Piauí (SOUZA e OLIVEIRA, 2006).

Souza e Oliveira (2006), também classificam o Brejo da Borborema como enclave subúmido, disposto entre os estados de Paraíba, Pernambuco e Alagoas, o Enclave do Brejo da Borborema apresenta precipitação variantes entre $700 \mathrm{~mm}$ podendo chegar em alguns municípios até $2.000 \mathrm{~mm}$ anuais, um clima mais úmido que proporcionará temperaturas mais amenas e solos mais profundos e presença de uma vegetação de porte mais arbóreo.

\section{CONSIDERAÇÕES FINAIS}

O semiárido brasileiro apresenta uma significativa variação paisagística, a interação entre os seus elementos abióticos, especialmente clima, solo, geomorfologia e geologia, proporcionarão diferentes arranjos vegetacionais, que por sua vez, darão margem para essa diversidade paisagística, que irão desde as áreas de planaltos, depressões até os enclaves subúmidos caracterizados por serem áreas de exceção.

Os enclaves subúmidos se destacam como áreas de grande importância tanto do ponto de vista ecológico, principalmente devido a existência de climas mais úmidos e uma vegetação mais desenvolvida, quanto do ponto de vista social, que utilizam a individualidade do arranjo natural para o desenvolvimento das atividades agrícolas que impulsionam a economia local, 
fato que acaba desencadeando uma problemática relacionada a preservação e conservação desses lugares.

Devido à importância dessas áreas para o desenvolvimento local, bem como, do ponto de vista ecológico, é necessário que haja medidas de gestão e análises para que possam ser desenvolvidas políticas de proteção a essas feições naturais ou culturais presentes no local.

\section{REFERÊNCIAS}

AB'SÁBER, A. N. O domínio morfoclimático semi-árido das Caatingas brasileiras, Geomorfologia. 1-39, 1974.

AB'SÁBER, A. N. Um conceito de geomorfologia à serviço das pesquisas sobre o Quaternário. Revista Brasileira Geomorfologia. São Paulo, v. 18, 1969.

AB'SÁBER, Aziz Nacib. Sertões e sertanejos: uma geografia humana sofrida. Estudos avançados, v. 13, n. 36, p. 7-59, 1999.

ANDRADE-LIMA, D. The Caatingas dominium. Revista Brasileira de Botânica 4: 149-163. 1981.

ARAÚJO FILHO, J. C. Relação Solo e Paisagem no Bioma Caatinga. XXXIII Congresso Brasileiro de Ciência do Solos. Aptdão pedoclimática das culturas dos feijões caupi e comum para o Estado de Alagoas. 2011.

BANDA, K.; DELGADO-SALINAS, A.; DEXTER, K.G.; LINARES-PALOMINO, R.; OLIVEIRA-FILHO, A.; PRADO, D.; PULLAN, M.; Quintana, C.; RIINA,R.; RODRÍGUEZ, G. M.; WEINTRITT, J.; ACEVEDO-RODRÍGUEZ, P.; ADARVE, J.; ÁLVAREZ, E.; ARANGUREN, A.; ARTEAGA, J.C.; AYMARD, G.; CASTAÑO, A.; CEBALLOS-MAGO, N.; COGOLLO, A.; CUADROS, H.; DELGADO, F.; DEVIA, W.; DUEÑAS, H.; FAJARDO, L.; FERNÁNDEZ, A.; FERNÁNDEZ, M.A.; FRANKLIN, J.; FREID, E.H.; GALETTI, L.A.; GONTO, R.; GONZÁLEZ-M, R.; GRAVESON, R.; HELMER, E.H.; IDÁRRAGA, A.; LÓPEZ, R.; MARCANO-VEJA, H.; MARTÍNEZ, O. G.; MATURO, H.M.; MCDONALD, M.; MCLAREN, K.; MELO, O.; MIJARES, F.; MOGNI, V.; MOLINA, D.; MORENO, N. P.; NASSAR, J.M.; NEVES, D.M.; OAKLEY, L.J.; OATHAM, M.; OLVERA-LUNA, A.R.; PEZZINI, F.F.; DOMINGUEZ, O.J.R.; RÍOS, M.E; RIVERA, O.; RODRÍGUEZ, M.; ROJAS, A.; SÄRKINEN, T.; SÁNCHEZ, R.; SMITH, M.; VARGAS, C.; VILLANUEVA, B.; PENNINGTON, R.T.; Plant diversity patterns in neotropical dry forests and their conservation implications. Science, v. 353, n. 6306, p. 1383-1387, 2016.

BERTRAND, G. Paysage et géographie physique globale: esquisse méthodologique. Revue géographique des Pyrénées et sud-ouest, v. 39, fasc. 3, p. 249-272. 1968

BESSE, Jean-Marc. Ver a Terra: seis ensaios sobre a paisagem e a geografia. Trad. Vladimir Bartalini. São Paulo: Perspectiva, 2006.

BÉTARD, F.; PIERRE, J.; SALES, V. C. Caracterização Morfopedólogica de uma Serra Úmida no Semi-Árido do Nordeste brasileiro: o caso do maciço de Baturité-CE. Mercator Revista de Geografia da UFC. n12, 2007. p. 107-126.

BRANCO, S. M. Ecossistêmica: uma abordagem integrada dos problemas do meio ambiente. São Paulo: Edgard Blücher, 143p. 1989.

CASSETTI, V. Ambiente e apropriação do relevo. São Paulo: Contexto, 1991.

CASTELLETTI, C.H.M.; SILVA, J.M.C.; TABARELLI, M.; SANTOS, A.M.M. Quanto ainda resta da Caatinga? Uma estimativa preliminar. In: SILVA J.M.C. TABARELLI, M. \& FONSECA, M.T. (Orgs.). Biodiversidade da Caatinga: áreas e ações prioritárias para a conservação. Ministério do Meio Ambiente, Brasília, 2004. 
CAVALCANTI, Lucas Costa de Souza. Da descrição de áreas à teoria dos geossistemas: uma abordagem epistemológica sobre sínteses naturalistas. Pernambuco, 2013. 218p.

CERVANTES-BORJA, J.; ALFARO-SÁNCHEZ, G. La ecologia del paisaje en el contexto Del desarrollo sustentable. In: Salinas Cháves, Eduardo; Middleton, John. (Orgs.) La ecologia del paisaje como base para el desarrollo sustentable em América Latina, 1998.

CHRISTOFOLETTI, A. Desenvolvimento da quantificacao em geografia. Geociencias, n. especial, p. 67-78, 1990.

CHRISTOFOLETTI, Antonio. A aplicação da abordagem em sistemas na geografia física. Revista Brasileira de Geografia, v. 52, n. 2, p. 21-35, 1990.

CHRISTOFOLETTI, Antonio. Análise de Sistemas em Geografia. São Paulo: Hucitec, 1979. CHRISTOFOLETTI, Antonio. Modelagem de Sistemas Ambientais. São Paulo: Edgard Blücher, 1999.

CIRILO, J. A. C. Políticas públicas de recursos hídricos para o semi-árido. Estudos Avançados, v.22, p.61-82, 2008.

CODEVASF-Companhia de Desenvolvimento do Vale do São Francisco. Inventário de projetos. 1999.

CORRÊA, A.C.B., TAVARES, B.A.C., MONTEIRO, K.A., CAVALCANTI, L.C.S., LIRA, D.R. Megageomorfologia e morfoestrutura do Planalto da Borborema. Revista do Instituto Geológico. p.35-52. 2010.

CORRÊA, A. C. B. Dinâmica geomorfológica dos compartimentos elevados do Planalto da Borborema, Nordeste do Brasil. Universidade Estadual Paulista-UNESP, Rio Claro-SP. Tese de Doutorado. 386p. 2001.

CREEL, J.E.B. El valor de los bienes y servicios que las Áreas Naturales Protegidas proveen a los mexicanos. México: The Nature Conservancy. 2009.

DALBEM, R. P. MOURA, Angelita Rolim de; JORGE, Felipe Vanhoni; MOROKAWA, Mayara; VALASKI, Simone. Delimitação de unidades de paisagem: conceito e método aplicados ao município de Paranaguá/PR/ Brasil. In: SIMPÓSIO BRASILEIRO DE GEOGRAFIA FÍSICA APLICADA, 11, p. 3429-3438. 2005.

DUPUIS-TATE M.-F. Le paysage fluvial des paysagistes d'aménagement, Revue de géographie de Lyon, v. 73, n 4, p. 285-292. 1998.

FEITOSA, Fernando AC et al. Estudos Hidrogeológicos de Bacias Sedimentares da Região Semiárida do Nordeste brasileiro. Brasília, Ministério de Minas e Energia Secretaria de Minas e Metalurgia-Serviço Geológico do Brasil, 2004.

FIERZ, M. M. A teoria do equilíbrio dinâmico em geomorfologia. Geousp - Espaço e Tempo, v. 19, n. 3, p. 605-629. 2016.

FRANÇA, Carmena Ferreira de; PIMENTEL, Márcia Aparecida da Silva; PROST, Maria Thereza Ribeiro da Costa. Geomorfologia e paisagem: contribuições à classificação de unidades de paisagem da região oriental da ilha de Marajó, norte do Brasil. Anais do VI Seminário Latino-Americano de Geografia Física II Seminário Ibero-Americano de Geografia Física. Universidade de Coimbra. Portugal, 10p. 2010.

FUNDAÇÃO JOAQUIM NABUCO - FUNDAJ. Semi-árido: Proposta de convivência com a seca. 2002.

GOETHE, J. W. As Afinidades Eletivas. São Paulo, Nova Alexandrina, 1992.

GOMES, Paulo Cesar da C. Geografia e Modernidade. Rio de Janeiro: Bertrand Brasil, 1996. GREGORY, K. J. A Natureza da Geografia Física. Rio de Janeiro: Bertrand do Brasil, 367p.1992.

HAIGH, M. J. Geography and general systems theory, philosophical homologies and current practice. Geoforum, 16(2): $191-203,1985$. 
HOWARD, A. D. Equilíbrio e dinâmica dos sistemas geomorfológicos. Noticia geomorfológica, v. 13, n. 26, p. 3-20, 1973.

INPE-Instituto Nacional de Pesquisas Espaciais. INPE Nordeste mapeia desmatamento da Caatinga. 2015. http://www.inpe.br/noticias/noticia.php?Cod_Noticia=3895

JACOMINE, P. K. T. Solos sob Caatinga: características e uso agrícola. In: ALVAREZ, V. H.; FONTES, L. E.; FONTES, M. P. F. O solo nos grandes domínios morfoclimáticos do Brasil e o desenvolvimento sustentado. Viçosa, MG: SBCS, p. 95-133.1996.

LEAL, Inara Roberta; DA SILVA, José Maria Cardoso. Ecologia e conservação da Caatinga. Editora Universitária UFPE, 2003.

LIMA, Fabiana Silva de; ALMEIDA, Nadjacleia Vilar. Dinâmica Espaço-temporal da Cobertura Vegetal na Área de Proteção Ambiental (APA) do Cariri, Paraíba-PB, Brasil (Spatial and temporal dynamic of the vegetation cover in the environmental protection area (EPA) of Cariri, Paraíba-PB, Brasil). Revista Brasileira de Geografia Física, v. 10, n. 3, p. 699-721, 2017.

LIMBERGER, L., 2006. Abordagem sistêmica e complexidade na Geografia. Revista Geografia. 15, 95-109.

LOIOLA, Maria Iracema Bezerra; ROQUE, Alan de Araújo; OLIVEIRA, Ana Claudia Pereira de. Caatinga: Vegetação do semiárido brasileiro. Revista Ecologia, p.14-19. 2012.

MAIA, Gerda Nickel. Caatinga árvores e arbustos e suas utilidades. Leitura \& Arte, 2004. MALVEZZI, Roberto. Semi-árido - uma visão holística. Brasília, 140p. 2007.

MANTELATTO, F. L. M.; CHRISTOFOLETTI, R. A. Natural feeding activity of the crab Callinectes ornatus (Portunidae) in Ubatuba Bay (São Paulo, Brazil): influence of season, sex, size and molt stage. Marine Biology, v. 138, n. 3, p. 585-594, 2001.

MARQUES NETO, Roberto. A abordagem sistêmica e os estudos geomorfológicos: algumas interpretações e Possibilidades de Aplicação. Revista Geografia - v. 17, n. 2. Londrina, 21p. 2008.

MATALLO JUNIOR., H. A desertificação no mundo e no Brasil. In: SCHENKEL, C. S. e MATALLO JR, H (Org). Desertificação. Brasília: UNESCO, 2003.

MENDOZA, Josefina G. Et Alii. El Pensamiento Geografico. Barcelona: Alianza Editorial, 1988.

MMA-Ministério do meio ambiente. Monitoramento dos biomas brasileiros: Bioma Caatinga. 2010.

MIN-Ministério da Integração Nacional. Relatório final Grupo de trabalho para delimitação do Semiárido. 2017. http://sudene.gov.br/images/2017/arquivos/Item_1.6.6__Relat\%C3\%B3rio_final_do_GT_Delimita\%C3\%A7\%C3\%A3o_do_Semi\%C3\%A1rido.pdf MOLINA, P. H., El paisaje natural en la confluencia de los ríos Jarama y Manzanares (Madrid). Ería. Departament de Geografía de la Universidad de Oviedo. p. 105- 123. Oviedo, 1992.

MONTEIRO, C. A. F. Geossistemas: a história de uma procura. São Paulo: Contexo, 127p. 2000.

PASSOS, Messias; DUBREUIL, Vincent. A relação clima-vegetação no semi-arido brasileiro. Boletim de geografia, v. 22, n. 1, p. 35-48, 2004.

PEIXOTO, Filipe da Silva; SALES, Marta Celina Linhares. Análise de Microclimas na Cidade de Viçosa do Ceará: Abordagem na Perspectiva do Conforto Térmico (Analysis of the Microclimate in Viçosa Ceará: Approach in View of Thermal Comfort). Revista Brasileira de Geografia Física, v. 5, n. 1, p. 47-58, 2012.

PEREIRA, A.R.; ANGELOCCI, L.R.; SENTELHAS, P.C. Agrometeorologia: fundamentos e aplicações práticas. Gauíba: Livraria e Editora Agropecuária Ltda., 478p. 2010. 
PHILLIPS, J. D. Divergent evolution and the spatial structure of soil landscape variability. Catena, Amsterdam, v. 43, p. 101-113, 2001.

PHILLIPS, J. D. The perfect landscape. Geomorphology, v. 84, p. 159-169, 2007.

PRADO, Darién E. As caatingas da América do Sul. Ecologia e conservação da Caatinga, v. 2, p. 3-74, 2003

PRICHOA, Carla Eva; RIBEIRO, Selma Regina Aranha; HOLGADO, Pedro Molina. Aplicação da análise visual em duas unidades de paisagem da bacia hidrográfica do rio Pitangui, PR, mediante processamentos digitais. Terr@Plural, Ponta Grossa, v.8, n.1, p. 185-201, 2014. PRIGILL, Phillip. VOLKMAN, Nancy. Landscapes in History. New York: John Wiley \& Sons, 1998.

REICH, Peter B.; BORCHERT, Rolf. Water stress and tree phenology in a tropical dry forest in the lowlands of Costa Rica. The Journal of Ecology, p. 61-74, 1984.

RENWICK, William H. Equilibrium, disequilibrium, and nonequilibrium landforms in the landscape. Geomorphology, vol. 5. 1992. p.265-276.

ROCHA, A.V.; SHAVER, G.R. Advantages of a two band EVI calculated from solar and photosynthetically active radiation fluxes. Agricultural and Forest Meteorology, 149(9), p.1560-1563. 2009.

RODAL, Maria Jesus Nogueira et al. Flora de um Brejo de Altitude na escarpa oriental do planalto da Borborema, PE, Brasil. Acta Botanica Brasilica, v. 19, n. 4, p. 843-858, 2005.

ROSS, J.L.S. O registro cartográfico dos fatos geomórficos e a questão da taxonomia do relevo.

Revista do Departamento de Geografia. n.6, p. 17-29, 1992.

SÁ, I. B.; RICHÉ, G. R.; FOTIUS, G. A. As paisagens e o processo de degradação do semiárido nordestino. In: Silva, J.M.C.; Tabarelli, M.; Fonseca, M.T. da.: Lins, L.V. (Org.). Biodiversidade brasileira: avaliação e identificação de áreas e ações prioritárias para conservação. Brasília: Ministério do Meio Ambiente, 2004, p. 17-36.

SANTOS, Cícero Félix dos; SCHISTEK, Haroldo. OBERHOFER, Maria. Conhecendo o Semi-árido em Busca da Convivência. 48p. 2007.

SCHAMA, Simon. Paisagem e Memória. São Paulo: Companhia das Letras, 1996.

SCHEIDEGGER, Adrian E. Limitations of the system approach in geomorphology. Geomorphology, v. 5, n. 3-5, p. 213-217, 1992.

SILVA, D. N. F. Reconstrução da paisagem geomorfológica através da assinatura geoquímica dos eventos deposicionais da bacia do rio Capibaribe-Mirim, Pernambuco. Dissertação de Mestrado, Programa de Pós-graduação em Geografia, Universidade Federal de Pernambuco, 167p. 2012.

SOTCHAVA, V. B. O estudo dos geossistemas. Métodos em Questão. São Paulo, n. 6, 1977. $50 \mathrm{p}$.

SOUZA FILHO, M.; Sales, M. C. L. Microclimas urbanos nos enclaves úmidos do ceará: o caso de ubajara. Anais do XII Encontro de Geográfos da America Latina. 2009

SOUZA, Marcos José Nogueira de; OLIVEIRA, Vládia Pinto Vidal de. Os Enclaves Úmidos e Sub-Úmidos do Semi-Árido do Nordeste Brasileiro. Mercator, n. 09, 18p. 2006.

SUDENE- Superintendência do Desenvolvimento do Nordeste. Mapa geológico: escala 1:25.000.000. 1974.

TABARELLI, Marcelo; VICENTE, A.; BARBOSA, D. C. A. Variation of seed dispersal spectrum of woody plants across a rainfall gradient in north-eastern Brazil. Journal of Arid Environments, v. 53, n. 2, p. 197-210, 2003.

THORNTHWAITE, Charles Warren. An approach toward a rational classification of climate. Geographical review, v. 38, n. 1, p. 55-94, 1948. 
VELOSO, Henrique Pimenta; RANGEL-FILHO, Antonio Lourenço Rosa; LIMA, Jorge Carlos Alves. Classificação da vegetação brasileira, adaptada a um sistema universal. IBGE, 1991.

VERSTAPPEN, H.TH. Applied Geomorphology: geomorphological surveys for environmental development. Elsevier, Amsterdam, 437p. 1983.

VITTE, A. C. Kant, Goethe e Alexander Humboldt: Estética e paisagem na gênese da geografia física moderna. Revista ACTA Geografia, Ano IV, n. 8, p. 07-14. 2010.

VITTE, A. C. O Desenvolvimento do conceito de paisagem e sua inserção na geografia física. Revista Mercator, n. 11, p.71-78. 2007.

VITTE, Antonio Carlos; DA SILVEIRA, Roberison Wittgeinstein Dias. Kant, Goethe e Alexander Humboldt: Estética e Paisagem na Gênese da Geografia Física moderna. ACTA GEOGRÁFICA, v. 4, n. 8, p. 07-14, 2010. 